\title{
El Estado social y la fragilidad de los derechos sociales en tiempos de crisis económica ${ }^{1}$
}

\author{
Luis E. Delgado del Rincón \\ Profesor Titular de Derecho Constitucional \\ Universidad de Burgos
}

\begin{abstract}
Sumario: 1. Estado social, crisis económica y derechos sociales. - 2. La «reserva de lo posible» y el principio de prohibición de retroceso social o de irreversibilidad de los derechos sociales.-3. Un derecho especialmente debilitado: el derecho a la asistencia sanitaria de los inmigrantes irregulares.-4. A modo de conclusión.
\end{abstract}

\section{ESTADO SOCIAL, CRISIS ECONÓMICA Y DERECHOS SO- CIALES}

El surgimiento de la forma del Estado social supuso la intervención del Estado en los ámbitos social y económico para promover la justicia social y garantizar la igualdad real y efectiva entre los ciudadanos. Algunas de las propuestas innovadoras de este modelo de Estado son el reconocimiento y defensa de determinados derechos como el derecho a una educación universal y gratuita, el derecho al trabajo, el derecho a la asistencia sanitaria, o también la creación de una organización económico-política que sea capaz de asegurar la protección de la tercera edad o la tutela frente a determinados infortunios, como el desempleo ${ }^{2}$. En definitiva y como es sabido, se crean, con

${ }^{1}$ Este trabajo es el resultado de una ponencia invitada que se impartió el día 22 de marzo de 2013, en el Congreso sobre La crisi economica ed $i$ suoi riflessi sull'ordinamento costituzionale, organizado por la Scuola Superiore Sant'Anna, Istituto DIRPOLIS y la Università di Pisa, Dipartimento di Giurisprudenza. El trabajo se ha realizado también en el marco de los Proyectos de investigación DER2008-00185/JURI, sobre Pluralidad de Ciudadanías y participación democrática, concedido por la Subdirección de Proyectos de Investigación del Ministerio de Ciencia e Innovación (2008-2012) y VA005A10-1, sobre Integración social y ciudadana de los inmigrantes en Castilla y León, concedido por la Consejería de Educación de la Junta de Castilla y León (2010-2012). El texto que se presenta para su publicación tiene su origen en el utilizado para la exposición oral, aunque se le ha incorporado la bibliografía correspondiente y se han ampliado y actualizado algunos de los argumentos e informaciones que contenía. Aún así, mantiene algunas licencias propias de la versión oral originaria.

${ }^{2}$ Acerca del Estado social, sus fines y la interacción entre el Estado y la sociedad en esta forma de organización política, vid., entre otros, García Pelayo, M., Las transformaciones del Estado contemporáneo, Obras Completas, vol. II, Centro de Estudios Políticos y Constitucionales, Madrid, 2009, pp. 1599-1619; Авendroth, W., Forsthoff, E. y Doenring, K., El Estado Social, Centro de Estudios Políticos y Constitucionales, 
esta forma de Estado, un nuevo tipo de derechos, los derechos sociales o derechos de prestación, que se conciben como instrumentos necesarios en manos de los poderes públicos para garantizar las condiciones precisas en virtud de las cuales la libertad e igualdad sean reales y efectivas (arts. 3.2 y 9.2 y de las Constituciones italiana y española (CE).

Los derechos sociales son una categoría heterogénea y compleja que comprende diversas realidades, que se descompone en múltiples figuras jurídicas con sus correspondientes técnicas de protección. La mayoría de ellos atribuye a sus titulares la facultad de reclamar del Estado determinadas prestaciones, las cuales están relacionadas con las condiciones por las que el individuo se inserta en la sociedad (aunque existan excepciones como los derechos laborales, esto es, los derechos de huelga y de libre sindicación, o el derecho al medioambiente) ${ }^{3}$.

Es cierto que los derechos sociales constituyen una manifestación de la igualdad real y de la justicia material, pero también lo serán de la libertad y de la democracia. Así, la educación, la protección de la salud, o el mantenimiento de un régimen público de Seguridad Social son condiciones necesarias (aunque no suficientes) de la libertad. En otras palabras, los derechos sociales no sólo son una exigencia del Estado social sino también de un Estado de derecho (de unos poderes públicos sometidos al Derecho, a las normas constitucionales reconocedoras de los derechos sociales) y de un Estado democrático (puesto que sin derechos sociales efectivos no hay verdadera ciudadanía, sino una sociedad de castas $)^{4}$.

Madrid, 1986, pp. 13-15, 77 y ss.; Garrorena Morales, A., El Estado español como Estado social y democrático de Derecho, Tecnos, Madrid, 1994, pp. 29-44; del mismo autor Derecho Constitucional. Teoría de la Constitución y sistema de fuentes, Centro de Estudios Políticos y Constitucionales, Madrid, 2011, pp. 149-156; FernÁndEZ-Miranda CAmpoamor, A., «El Estado social», Revista Española de Derecho Constitucional, nº 69, 2003, pp. 143-147.

${ }^{3}$ Sobre la categoría de los derechos sociales en la forma de Estado social, vid., en general, Cossio Diaz, J.R., Estado social y derechos de prestación, Centro de Estudios Políticos y Constitucionales, Madrid, 1989, pp. 121 y ss.; Fernández-Miranda Campoamor, A., «El Estado social...», ob. cit., pp. 154-161; Carmona Cuenca, E., El Estado Social de Derecho en la Constitución, Consejo Económico y Social, Madrid, 2000, pp. 148-164; Courtis, C. y Abramovic, V., Los derechos sociales como derechos exigibles, Trotta, Madrid, 2002, pp. 19-64; Díez Picazo, L. Ma., Sistema de derechos fundamentales, Thomson Civitas, Navarra, 2008, pp. 68-70 y 511 y ss. y CASCAJo CASTRo, J.L., La tutela constitucional de los derechos sociales, Centro de Estudios Políticos y Constitucionales, Madrid, 1988, pp. 35 y ss.; y también del mismo autor, «Derechos sociales». En Cascajo Castro, José Luis, Terol Becerra, Manuel, Domínguez Vila, Antonio y Navarro Marchante, Vicente (coords.): Derechos sociales y principios rectores, Tirant lo blanch, Valencia, 2012, pp. 21-26.

${ }^{4}$ Cfr. Rey Martínez, F., «Derribando falacias sobre derechos sociales». En Cascajo Castro, José Luis, Terol Becerra, Manuel, Domínguez Vila, Antonio y Navarro Marchante, Vicente (coords.): Derechos sociales y principios rectores, Tirant lo blanch, Valencia, 2012, p. 634. Acerca del significado jurídico y de la interrelación entre las cláusulas del 
A diferencia de los derechos civiles, de los derechos de libertad individual, que son directa e inmediatamente exigibles ante los tribunales desde su reconocimiento en la norma constitucional (sin necesidad de mediación alguna); los derechos sociales solamente serán tutelables judicialmente a partir de su desarrollo legislativo.

La razón de esta diferencia radica en que, para los derechos civiles, la Constitución es capaz, por sí misma, de identificar suficientemente su contenido (las facultades que lo integran) y de tutelar los ámbitos de autonomía y libertad de los ciudadanos frente a la acción de los poderes públicos. Sin embargo, la Constitución no puede especificar en qué forma los poderes públicos pueden intervenir en la sociedad para reducir las desigualdades sociales; es decir, no puede concretar el contenido de las prestaciones sociales en favor de los ciudadanos, ya que ello depende inevitablemente de la coyuntura económica y de cómo sea valorada ésta por la mayoría gobernante.

Desde este punto de vista, los derechos sociales no serían derechos fundamentales en sentido estricto, ya que, de un lado, carecen de un "contenido esencial» (constitucional) resistente a la acción del legislador y, de otro, porque no son tutelables de forma inmediata ante los tribunales 5 .

Sin embargo, para un sector de la doctrina, los derechos sociales son derechos fundamentales porque albergan dimensiones de libertad, igualdad

Estado social, Estado democrático y Estado de derecho, vid., entre otros, García Pelayo, M., Las transformaciones del Estado contemporáneo..., ob. cit., pp. 1619-1635; GARRoRena Morales, A., El Estado español como Estado social..., ob. cit., pp. 199-216; Cossio Diaz, J.R., Estado social ..., ob. cit., pp. 35-42; Fernández-Miranda Campoamor, A., «El Estado social...», ob. cit., pp. 140-142 y 151-154; CARmona Cuenca, E., El Estado Social de Derecho..., ob. cit., pp. 119-144; Pérez Royo, J., «Estado social de derecho», Temas Básicos de Derecho Constitucional, Tomo I. Organización general y territorial del Estado (dir. Manuel Aragón Reyes; codir. César Aguado Renedo), Civitas-Thomson Reuters, Navarra, 2011, pp. 191-194; Aragón Reyes, M., "Artículo 1», Comentarios a la Constitución española (XXX aniversario), (dirs.: Casas Baamonde, María Emilia y Rodríguez-Piñero Bravo-Ferrer, Miguel; coords.: Borrajo Iniesta, Ignacio y Pérez Manzano, Mercedes), Fundación Wolters Kluwer, Toledo, 2009, pp. 33-36.

${ }^{5}$ En general, sobre la eficacia jurídica y garantías de los derechos sociales en el Derecho español, cfr. Fernández-Miranda CAMPOAmor, A., «El Estado social...», ob. cit., pp. 157-161; SolozÁbal Echevarría, J. J., «Una revisión de la teoría de los derechos fundamentales», Revista jurídica Universidad Autónoma de Madrid, nº 4 (2001), pp. 110113; Requejo Pagés, J.L., «Derechos de prestación», Temas Básicos de Derecho Constitucional, Tomo III. Organización general y territorial del Estado (dir. Manuel Aragón Reyes; codir. César Aguado Renedo), Civitas- Thomson Reuters, Navarra, 2011, pp. 7678; Jiménez CAmpo, J., Derechos fundamentales. Concepto y garantías, Trotta, Madrid, 1999, pp. 121-132; Tenorio, P. «El Tribunal Constitucional, la cláusula del Estado social, los derechos sociales y el derecho a un mínimo digno». En Cascajo Castro, José Luis, Terol Becerra, Manuel, Domínguez Vila, Antonio y Navarro Marchante, Vicente (coords.): Derechos sociales y principios rectores, Tirant lo blanch, Valencia, 2012, pp. 260-272 y CASCAJO CAstro, J.L., La tutela constitucional de los derecho..., ob. cit., pp. 65-94, y del mismo autor «Derechos sociales...», ob. cit., pp. 38-43. 
y democracia; sin perjuicio de que se admita que algunos de ellos requieren prestaciones públicas y que, como tales, dependen de los recursos económicos disponibles y de las prioridades de gasto fijadas por la mayoría política de turno. Para este sector doctrinal, todos los derechos, también los derechos de libertad cuestan dinero. Exigen, por ejemplo, el mantenimiento de un sistema de orden público, o la creación de unos tribunales y la dotación de unos medios personales y materiales. Incluso precisan de una previa configuración legal. En definitiva, cuando se afirma que los derechos sociales están condicionados por lo económicamente posible, dicha condición no sólo es aplicable a los derechos sociales, sino también a los civiles ${ }^{6}$.

En la Constitución española, para hacer más visible la cláusula del Estado social, se procedió a una enumeración amplia de los derechos sociales. Ésta se recoge en el capítulo III del Título I, bajo la rúbrica de los "principios rectores de la política social y económica». La desactivación como verdaderos derechos fundamentales se deduce de lo establecido en el art. 53.3 CE, cuando dice que dichos principios «informarán la legislación positiva, la práctica judicial y la actuación de los poderes públicos». Solamente «podrán ser alegados ante la jurisdicción ordinaria de acuerdo con lo que dispongan las leyes que lo desarrollen». Se construyen así como derechos de configuración legal. Otro problema sería el que resulte de la inactividad total del legislador para elaborar una ley que dote de contenido a los principios rectores reconocidos en la Constitución, respecto del cual nuestro ordenamiento jurídico, a diferencia de otros como el portugués, no ha previsto un mecanismo de control de constitucionalidad por la omisión total del legislador?.

${ }^{6}$ Vid., entre otros, Rey Martínez, F., «Derribando falacias sobre derechos sociales...», ob. cit., pp. 638-639; Courtis, C. y ABramovic, V., Los derechos sociales como..., ob. cit., pp. 85-89; Escobar Roca, G., «Los derechos fundamentales sociales y la protección de la salud», Revista de Derecho Político, no 71-72, 2008, pp. 111-114 y la obra dirigida por este autor Derechos sociales y tutela antidiscriminatoria, Aranzadi-Thomson Reuters, Navarra, 2012; SARLET, I.W., «Los derechos sociales a prestaciones en tiempos de crisis». En Miguel Ángel Presno Linera (coord.): Crisis económica y atención a las personas y grupos vulnerables, Procuradora General del Principado y la Cátedra de amparo de derechos y libertades, Oviedo, 2012, pp. 5-6: (http://www.procuradorageneral.es/catedra/libro_digital_procura.php). Otros autores prefieren hablar de los derechos sociales como derechos en «permanente minoría de edad» o «derechos fundamentales in fieri», CASCAJO CASTRO, J.L., «Derechos sociales...», ob. cit., pp. 23 y 36-38; o de la existencia de unos derechos que son más fundamentales que otros ("fundamentalidad gradual»), atendiendo a su mayor o menor preservación normativa a favor de su titular y frente al legislador, BASTIDA FREIJEDO, F. J., «¿Son los derechos sociales derechos fundamentales?». En Robert Alexy, Derechos sociales y ponderación, Fundación Coloquio Jurídico Europeo, Madrid, 2009, pp. 105 y 138 y ss. (http://www.fcje.org.es/ wp-content/uploads/file/Libros_Publicados/ Cuadernos_Fundacion/DERECHOS_SOCIALES_Y_PONDERACION.pdf)

${ }^{7}$ Sin perjuicio de que en algunos casos se haya recurrido por el Tribunal Constitucional a la utilización de sentencias aditivas, apreciando una inconstitucionalidad por omisión con vulneración del principio de igualdad. Al problema de la injerencia del Tribunal 
Ahora bien, de lo expuesto en el art. 53.3 CE no puede desprenderse que el reconocimiento constitucional de los derechos sociales sea irrelevante o que carezca de toda eficacia jurídica. Por el contrario, de su proclamación constitucional puede deducirse la siguiente eficacia jurídica:

En primer lugar, poseen una eficacia interpretativa, ya que las normas constitucionales que los reconocen pueden ser utilizadas por los jueces como criterio interpretativo de las leyes que otorgan prestaciones. En este sentido, el Tribunal Constitucional español, en temprana jurisprudencia, declaró que el art. 53.3 CE impide considerar a los principios del Capítulo III del Título I "como normas sin contenido y que obliga a tenerlos presentes en la interpretación tanto de las restantes normas constitucionales como de las leyes» (STC 19/1982, de 5 de mayo, FJ 6).

En segundo lugar, posibilitan el control de constitucionalidad de las leyes de desarrollo, pudiendo declararse inconstitucional una ley que se oponga frontalmente a la declaración de un derecho social, tal y como se define e identifica en la Constitución (por ejemplo, una ley que prevea un régimen privado de la Seguridad Social, cuando la Constitución establece en el art. 41 un «régimen público» de Seguridad Social) ${ }^{8}$. También, en reiterada jurisprudencia, el Tribunal Constitucional ha considerado a los principios rectores como posible canon o medida de validez de la ley.

Actualmente, el contexto socioeconómico y la situación de crisis económica existente, agudiza, si cabe aún más, la crisis del Estado social. Conviene recordar que comienza a hablarse de crisis del Estado de bienestar a partir de los años setenta del siglo pasado, con la crisis del petróleo que provocó una disminución del crecimiento y un aumento de la inflación y el desempleo en los países europeos, los cuales, hasta esa época, habían experimentado un periodo de crecimiento y estabilidad económica, que les permitió ampliar las prestaciones sociales a los ciudadanos. Desde entonces, se ha detenido ese proceso de expansión continua del Estado social, que se hace más patente a partir del momento en que aumenta la preocupación por controlar el déficit y la deuda pública, y cuando los Bancos centrales, en detrimento de los Gobiernos, asumen el control de la política monetaria precisamente para controlar la inflación. No obstante, y aunque desde hace décadas comienzan a conocerse los límites del Estado de bienestar, éste aún pervive, hasta el punto de que las cifras de gasto en

Constitucional en la actividad del legislador (innovando el ordenamiento jurídico), habría que añadir también el de su incidencia en el principio de la estabilidad presupuestaria. Vid., sobre el particular, Giménez SÁnchez, I., «Límites económicos de los derechos sociales». En Cascajo Castro, José Luis, Terol Becerra, Manuel, Domínguez Vila, Antonio y Navarro Marchante, Vicente (coords.): Derechos sociales y principios rectores, Tirant lo blanch, Valencia, 2012, pp. 309-312.

${ }^{8}$ Acerca de este ejemplo concreto, cfr. Mercader Ugina, J.R., «Artículo 41», Comentarios a la Constitución española (XXX aniversario), (dirs.: Casas Baamonde, María Emilia y Rodríguez-Piñero Bravo-Ferrer, Miguel; coords.: Borrajo Iniesta, Ignacio y Pérez Manzano, Mercedes), Fundación Wolters Kluwer, Toledo, 2009, pp. 1044-1045, que lo define como garantía institucional. 
prestaciones sociales, lejos de haber descendido, han aumentado considerablemente, entre otros motivos, por el envejecimiento de la sociedad y la disminución de la población activa, con el riesgo de quiebra del sistema de protección social (una sanidad cada vez más cara y un mayor número de pensiones) ${ }^{9}$. A lo que ha de añadirse el aumento del nivel de desempleo que exige, a su vez, una mayor financiación para atender más situaciones de desamparo.

Aún así, puede que estemos asistiendo actualmente a una nueva situación como consecuencia del tipo de crisis económica en la que nos hallamos inmersos. Crisis que comenzó siendo financiera, a causa de la falta de mecanismos de supervisión, y que luego se trasladó a la economía real. En poco tiempo, el Fondo Monetario Internacional pasó de recomendar a los Gobiernos que adoptasen políticas de estímulos fiscales a amenazarles con la intervención si no aplicaban unas drásticas políticas de austeridad. La consecuencia ha sido la implantación progresiva de tajantes recortes de prestaciones sociales ${ }^{10}$.

En España, donde el gasto social había aumentado claramente en los últimos años y donde incluso se habían reconocido nuevas prestaciones sociales -algunas sin anclaje constitucional, aunque sí estatutario- como las relacionadas con la atención a la dependencia (el cuarto pilar del Estado de bienestar) o las rentas mínimas de inserción, se dictan varios Decretos leyes, en los que para reducir el déficit, incorporan medidas como el aumento de la carga tributaria, el copago para la satisfacción de ciertas prestaciones sociales, la disminución de los salarios de los empleados públicos, o la congelación de las pensiones. La fuerte destrucción de empleo está provocando un elevado déficit en la Seguridad Social que impide revalorizar las pensiones. Para garantizar la sostenibilidad del sistema, el Gobierno ha aprobado y enviado a las Cortes un proyecto de ley de reforma de las pensiones que vincula la actualización anual de las pensiones a la evolución de los ingresos y gastos del sistema de Seguridad Social y no al Índice de Precios al Consumo (IPC); lo que redundará en una pérdida del poder adquisitivo de los pensionistas y en una disminución del consumo ${ }^{11}$.

${ }^{9}$ Vid. Fernández-Miranda Campoamor, A., «El Estado social...», ob. cit., pp. 147148 y Bilbao Ubillos, J.Ma., Rey Martínez, F. y Vidal Zapatero, J.M., Lecciones de Derecho Constitucional..., ob. cit., pp. 172-173.

${ }^{10}$ Cfr. Bilbao Ubillos, J.Ma ., Rey Martínez, F. y Vidal Zapatero, J.M., Lecciones de Derecho Constitucional..., ob. cit., p. 173.

${ }^{11}$ El proyecto de ley reguladora del factor de sostenibilidad y del Índice de revalorización del sistema de pensiones de la Seguridad Social contempla sustituir el IPC, como coeficiente de actualización de las pensiones, por otro elemento que tendrá en cuenta la inflación y la evolución de los ingresos y gastos del sistema, con un incremento mínimo del $0,25 \%$, en situaciones de dificultad económica, que podrá recuperarse, en situaciones de bonanza, hasta un máximo del IPC más el 0,25\%. Cfr. la página web de la Moncloa, viernes, 27 de septiembre de 2013: (http://www.lamoncloa.gob.es/ConsejodeMinistros/ Resumenes/2013/270913-consejo.htm). 
En otras palabras, el objetivo de reducción del déficit (España ha llegado, en 2012, al 6,7, todavía lejos de alcanzar los objetivos fijados por el pacto de estabilidad en la Unión Europea) $)^{12}$ ha conllevado importantes restricciones en las partidas de gasto de los presupuestos públicos. Estas restricciones presupuestarias vienen impuestas no sólo por el volumen de déficit sino también por su composición, propia de la coyuntura actual de crisis económica. En este sentido, ha caído considerablemente la actividad productiva, y aún más el empleo, descienden los ingresos al tiempo que se eleva el gasto provocado por la necesidad de cubrir las prestaciones por desempleo. Todo ello deja muy poco margen a la financiación de programas de gasto destinados a satisfacer otras prestaciones sociales. Dentro del panorama europeo, en España, la contracción económica descrita es especialmente intensa porque, a la crisis financiera internacional, se ha sumado una devastadora crisis del sector inmobiliario, con un gran volumen de deuda privada que lastra pesadamente la reactivación del crédito ${ }^{13}$.

En resumen, el diagnóstico de la crisis del Estado social, agravada por la crisis económico-financiera de escala mundial y con una clara repercusión en los derechos sociales, podría caracterizarse, entre otros, por los siguientes factores que conforman una alteración sustancial de las condiciones estructurales de dicho modelo de Estado:

1) Existencia de unos alarmantes niveles de paro (casi seis millones de personas en España a finales de 2012: el 26,02 \% de la población laboral activa, con un 55,12\% de paro juvenil) ${ }^{14} \mathrm{y}$ dependencia de un número elevado de personas (cada vez mayor) de las políticas de asistencia social del Estado y de la beneficencia de algunas instituciones privadas (Caritas, Cruz Roja o el Banco de Alimentos). Esta situación está dando lugar a la aparición de bolsas de pobreza entre la población, hasta ahora desconocidas, con el peligro de exclusión social de algunos sectores de la sociedad y, por consiguiente, del aumento de la desigualdad social (en 2012, el 21,1 \% de la población españo-

${ }^{12}$ Reuters España:

(http://es.reuters.com/article/businessNews/idESMAE92501L20130306).

${ }_{13}$ Acerca de estas restricciones presupuestarias para reducir el déficit, vid., en general, Vaquer Caballería, M., «Derechos sociales, crisis económica y principio de igualdad». En Informe Comunidades Autónomas 2011, Instituto de Derecho Público, Barcelona, 2012, pp. 75-76; PreSno LinerA, M.A., «Introducción: lo esencial de la crisis sigue siendo invisible». En Miguel Ángel Presno Linera (coord.): Crisis económica y atención a las personas y grupos vulnerables, Procuradora General del Principado y la Cátedra de amparo de derechos y libertades, Oviedo, 2012, pp. 7-10: (http://www.procuradorageneral.es/ catedral libro_digital_procura.php y CARRILlo, M. «L'impacte de la crisi sobre els drets de l'àmbit social». Revista catalana de dret públic, no 46 (2013), pp. 49-50.

${ }^{14}$ Diario $A B C$, de 21 de febrero de 2013, según los datos de la Encuesta de Población Activa (EPA) hecha pública por el Instituto Nacional de Estadística (INE): (http://www. abc.es/ economia/20130124/ abci-datos-paro-empleo-201301240903.html). 
la malvive por debajo del umbral de pobreza $)^{15}$. En este sentido, algún autor ha advertido del riesgo de que pueda crearse un caldo de cultivo para el surgimiento de lo que ha denominado como una especie de «Apartheid Social» ${ }^{16}$.

2) Paradójicamente, como consecuencia de la crisis económica-financiera, el Estado ha tenido que inyectar, con cargo a sus presupuestos generales, cantidades significativas de dinero público a entidades bancarias (desde el año 2008 y hasta octubre de 2012, el Estado español, según una respuesta del Gobierno a una pregunta parlamentaria, ha aportado 52.548 millones de euros) ${ }^{17}$; o acudir a discutibles medidas como la concesión de incentivos fiscales (cuando no amnistías) a iniciativas privadas o particulares. Todo ello en detrimento de la disminución de la capacidad económica del Estado para afrontar la protección social de crecientes necesidades de la población y de asegurar la efectividad de los derechos sociales, de los derechos a prestaciones públicas.

3) La progresiva marginalidad social que está generando la crisis económica incide también en la seguridad pública, originando un aumento de la criminalidad y una vulneración de algunos derechos fundamentales. Esta situación ha llevado a algunos Gobiernos (como el español), con el apoyo de un sector de la opinión pública, a impulsar una reforma de la legislación penal para endurecer las penas o introducir nuevas medidas de seguridad, algunas de ellas de dudosa constitucionalidad y compatibilidad con el sistema de los derechos fundamentales (custodia de seguridad, prisión perpetua o prisión permanente revisable).

4) La escasez de recursos destinados a la atención de crecientes necesidades sociales, ha dado lugar también a que los poderes públicos establezcan tratamientos diferenciados entre colectivos sociales vulnerables, excluyendo del acceso a determinadas prestaciones a ciertos grupos como, por ejemplo, el de los extranjeros irregulares. Incluso puede advertirse la aparición de algunas conductas políticas xenófobas que critican el gasto público destinado a satisfacer necesidades básicas de los extranjeros, cuando los nacionales están demandando cada vez mayores prestaciones del Estado.

Estos factores ponen de manifiesto la densidad y eficacia jurídica limitada de la cláusula constitucional del Estado social, porque siendo una cláusula finalista que persigue una sociedad más justa e igualitaria, depende para la consecución de sus fines de diferentes opciones y de circunstancias políticas y económicas.

${ }^{15}$ Cfr. El Huffington Post, de 22 de octubre de 2012, de acuerdo los datos publicados por el Instituto Nacional de Estadística (INE) sobre las condiciones de vida de los españoles: (http://www.huffingtonpost.es/2012/10/22/el-211-de-los-espanoles-p_n_1999689.html)

${ }^{16}$ Vid. De Sousa Santos, B., Reinventar a Democracia, Gradivā, Lisboa, 1998, pp. 17-19, citado por SARLET, I.W., «Los derechos sociales a prestaciones...», ob. cit., p. 7.

${ }^{17}$ Cfr. Presno Linera, M.A., «Introducción: lo esencial de la crisis », ob. cit., p. 11. 


\section{LA «RESERVA DE LO POSIBLE» Y EL PRINCIPIO DE PROHI- BICIÓN DE RETROCESO SOCIAL O DE IRREVERSIBILIDAD DE LOS DERECHOS SOCIALES}

La satisfacción de los derechos prestacionales por los poderes públicos exige de estos una dotación de determinados medios materiales, personales y financieros. Se trata de derechos que tienen una dimensión económicamente relevante y que, por ello, dependen de los recursos disponibles y de las prioridades de gasto fijadas por los gobernantes de turno. El coste económico de los derechos sociales, que también se extiende a los derechos civiles, se relaciona con la denominada cláusula de la «reserva de lo posible», o con la escasez de recursos disponibles. Cláusula que se erige en un límite a la efectividad de los derechos sociales.

De acuerdo con esta noción de «reserva de lo posible», procedente del Derecho alemán ${ }^{18}$, la efectividad de los derechos sociales depende de la capacidad económica, financiera y presupuestaria del Estado, así como de la disponibilidad real de los recursos materiales y humanos, sin perjuicio de que puedan existir derechos sociales a prestaciones que sean económicamente neutros, en el sentido de que la satisfacción de las prestaciones pueda condicionarse al pago de tasas y precios públicos.

En situaciones de crisis económica, la disminución de los recursos disponibles para atender las prestaciones sociales hace necesario un debate público sobre el uso y destino de los recursos escasos. De ahí que corresponda a los poderes públicos la carga de demostrar la falta de recursos necesarios para facilitar a los ciudadanos prestaciones sociales, así como también la elección de la mejor forma de aplicar los recursos públicos escasos, esto es, la opción por una eficiente aplicación de los gastos.

En ocasiones, los poderes públicos pueden encontrarse con dificultades para establecer y fijar las prioridades de gasto, llegando incluso a distribuir los sacrificios de forma desigual entre los ciudadanos, con el consiguiente perjuicio para aquellos que se encuentren en posiciones vulnerables.

A título de ejemplo, puede citarse el Real Decreto ley 20/2012, de 13 de julio, de medidas para garantizar la estabilidad presupuestaria y de fomento de la competitividad. En él se aprueban, como reformas necesarias y urgentes y por exigencias de cumplimiento de los objetivos de déficit público, nuevos y numerosos recortes de derechos sociales e incrementos de impuestos, todos ellos establecidos sin apenas negociación política ni social: eliminación de una paga extraordinaria de los empleados públicos, suspensión de derechos colectivos y también de derechos de atención a situaciones de dependencia, rebajas de la protección por desempleo y subidas del Impuesto sobre el Va-

${ }^{18}$ Sobre el origen alemán de la expresión «reserva de lo posible» (asociada a la noción de escasez y de la disponibilidad de recursos), especialmente a partir de comienzos de los años setenta, cfr. SARLET, I.W., «Los derechos sociales a prestaciones...», ob. cit., pp. 1213 y la bibliografía citada. 
lor Añadido, del Impuesto sobre Sociedades, del Impuesto sobre la Renta de las Personas Físicas (en menor grado) y de los Impuestos Especiales. Eso sí, según se dice en la norma, sin menoscabo de la prestación de los servicios públicos esenciales. En contraste con estas medidas de recortes sociales y subida de impuestos, se aprueban también algunas normas, como el Real Decreto ley 26/2012, de 7 de septiembre, por el que se concede un crédito extraordinario en el presupuesto del Ministerio de Defensa para atender al pago de obligaciones correspondientes a programas especiales de armamento (1.782.770.890 euros), con los argumentos de evitar la «pérdida de empleos altamente cualificados y de capacidad exportadora de nuestra industria», o «para reforzar la imagen de España como socio fiable en los consorcios internacionales».

La «reserva de lo posible» es, pues, una categoría que opera como una especie de mandato de optimización de la eficacia de los derechos sociales, imponiendo al Estado el deber de promover las condiciones óptimas para asegurar la efectividad de las prestaciones públicas y tratando de preservar los niveles de protección ya alcanzados. Aspecto que conecta con otro problema, el del retroceso o no de las conquistas sociales, el de la reversibilidad o no de las normas reconocedoras de derechos sociales.

Para un sector de la doctrina, el principio de la irreversibilidad de los derechos sociales o de prohibición de retroceso de las conquistas sociales conecta con el principio de seguridad jurídica. Constituye una garantía de protección de los derechos sociales -y de la propia dignidad humana-, que cobra actualidad en tiempos de crisis económica, al poder invocarse frente al legislador cuando introduzca medidas de supresión o de restricción de prestaciones públicas ya existentes. Trata de preservar un mínimo existencial o un contenido esencial de los derechos sociales a prestaciones ya adquiridas ${ }^{19}$.

Desde este sector doctrinal se reivindica una eficacia negativa de los derechos sociales, concebidos así como derechos subjetivos de defensa, en virtud de los cuales podría reclamarse judicialmente una prohibición de intervención o de eliminación de determinadas posiciones jurídicas ya consolidadas. La garantía de prohibición del retroceso social tendría por objeto preservar el bloque normativo -constitucional e infraconstitucional- de los niveles de eficacia de los derechos sociales ya consolidados ${ }^{20}$.

Uno de los argumentos que se alegan para fundamentar la irreversibilidad (o no regresividad) de los derechos sociales es la cláusula de progresividad prevista en el art. 2.1 del Pacto Internacional de los Derechos Económicos, Sociales y Culturales, de 1966. Mediante ella se impone a los Estados

${ }^{19} \mathrm{Vid}$. SARLET, I.W., «Los derechos sociales a prestaciones...», ob. cit., pp. 18-21 y las aportaciones de la doctrina portuguesa a través de autores como Gomes Canotilho y Vital Moreira. También Courtis, C. y Abramovic, V., Los derechos sociales como..., ob. cit., pp. 93-94 y 113-115, particularmente sobre el alcance de la aplicación de la prohibición de la regresividad.

${ }^{20}$ Cfr. SARLEt, I.W., «Los derechos sociales a prestaciones...», ob. cit., pp. 18-19 y Courtis, C. y Abramovic, V., Los derechos sociales como..., ob. cit., pp. 112-113. 
parte (setenta signatarios) la progresiva realización (y protección) de los derechos sociales que se reconocen en el Pacto: «Cada uno de los Estados Parte en el presente Pacto se compromete a adoptar medidas, tanto por separado como mediante la asistencia y la cooperación internacionales, especialmente económicas y técnicas, hasta el máximo de los recursos de que disponga, para lograr progresivamente, por todos los medios apropiados, inclusive en particular la adopción de medidas legislativas, la plena efectividad de los derechos aquí reconocidos».

No obstante, desde esa posición doctrinal, se admite también la posibilidad de introducir ajustes, e incluso restricciones, a los derechos sociales mediante acciones legislativas, al igual que sucede con los derechos civiles y políticos, para salvaguardar otros derechos fundamentales e intereses constitucionale ${ }^{21}$. Ahora bien, es preciso que toda medida restrictiva de los niveles de protección social se someta al correspondiente control de constitucionalidad a través de los criterios de proporcionalidad y de razonabilidad y de respeto al núcleo esencial (mínimo «existencial») de los derechos sociales.

Algunos de los casos que, en el ámbito del Derecho comparado, pueden citarse como ejemplo de la aplicación del principio de prohibición de retroceso en materia de derechos sociales (aunque no siempre hagan referencia expresa al mismo y sí al control de las medidas legislativas restrictivas de derechos sociales) son las decisiones del Tribunal Constitucional de Portugal 509/2002, de 19 de diciembre (ingreso social de inserción) y del Tribunal Constitucional Federal de Alemania, de 9 de febrero de 2010 (legislación Hartz IV) y de 18 de julio de 2012. En el primer caso, el Tribunal portugués declara la inconstitucionalidad -por violación del principio de prohibición de retroceso- de un Decreto de la Asamblea de la República portuguesa que sustituyó un antiguo ingreso social mínimo garantizado por un nuevo ingreso social de inserción, excluyendo del beneficio a las personas con edades entre 18 y 25 años. La exclusión del ingreso social de inserción a las personas de esta franja de edad, sin prever algún tipo de protección social similar, supone, a juicio del Tribunal, un retroceso en el grado de realización ya alcanzado del derecho a la Seguridad Social, hasta el punto de violar el contenido mínimo de ese derecho. En la sentencia del Tribunal Federal alemán, de 9 de febrero de 2010, el Alto Tribunal declaró inconstitucionales la reforma de algunas normas del Código de Protección Social, al entender que los métodos de cálculo (no las cuantías) de algunas prestaciones sociales ordinarias (alimentación, vestido, ajuar doméstico..) y las reducciones aplicadas a ciertos colectivos (menores y jóvenes), no garantizaban un mínimo existencial o vital digno. El Tribunal entendía también que el legislador no había observado un procedimiento transparente, al no mostrar de forma clara y accesible a los ciudadanos los criterios utilizados para establecer el nivel de las prestaciones sociales. En la sentencia del Tribunal Constitucional alemán, de 18 de julio de 2012, se declaró inconstitucional el valor de la prestación

\footnotetext{
${ }^{21}$ Ibidem.
} 
pecuniaria que se asignaba, mediante una ley específica, a los demandantes de asilo en Alemania, con el argumento de que la prestación no aseguraba el citado mínimo existencial o vital ${ }^{22}$.

Los partidarios de este principio de prohibición de retroceso o de regresividad en materia de derechos sociales, consideran que aunque no sea posible conseguir una prohibición absoluta del retroceso social, el principio es un instrumento jurídico idóneo para reducir el impacto de la crisis económica sobre los derechos sociales, asegurando un mínimo existencial, un nivel mínimo de igualdad de oportunidades.

En España, la mayoría de la doctrina es contraria al principio de prohibición de retroceso social o de irreversibilidad de las conquistas sociales. $\mathrm{Su}$ admisión impediría la gobernación y la viabilidad del Estado. De ahí que quede en manos del legislador la oportuna corrección de situaciones que sean eventualmente insostenibles por circunstancias socioeconómicas ${ }^{23}$.

El Tribunal Constitucional español, cuando se le ha planteado la cuestión directa o indirectamente, tampoco ha aceptado el principio de la irreversibilidad de las conquistas sociales. Algunas de las decisiones en las que se pronuncia sobre esta cuestión son las siguientes:

En la STC 97/1990, de 24 de mayo, al interpretar el art. 50 CE, cuando alude a las «pensiones adecuadas y periódicamente actualizadas», el Tribunal recuerda que el concepto de «pensión adecuada» «no puede considerarse aisladamente, atendiendo a cada pensión singular, sino que debe tener en cuenta el sistema de pensiones en su conjunto, sin que pueda prescindirse de las circunstancias sociales y económicas de cada momento y sin que quepa olvidar que se trata de administrar medios económicos limitados para un gran numero de necesidades sociales».

En relación con el derecho a la seguridad social, del art. $41 \mathrm{CE}$, al que el Tribunal lo concibe como una garantía institucional (STC 37/1994, de 10 de febrero), se establece que «es un derecho de estricta configuración legal, disponiendo el legislador de libertad para modular la acción protectora del sistema en atención a circunstancias económicas y sociales que son imperativas para la propia viabilidad y eficacia de aquél» (SSTC 65/1987, de 21 de mayo, FJ 17 y 128/2009, de 1 de junio, FJ. 4). Para el Alto Tribunal, su garantía «no equivale al mantenimiento incólume del régimen establecido» (STC 37/1994), admitiendo por tanto su reversibilidad por el legislador.

${ }^{22}$ Sobre las decisiones citadas de los Tribunales Constitucionales portugués y alemán puede verse el trabajo de SARLET, I.W., «Los derechos sociales a prestaciones...», ob. cit., pp. 15 y 22. De la sentencia del Tribunal Constitucional Federal de Alemania, de 9 de febrero de 2010 y de la amplia reforma del Código de Protección Social (la denominada legislación Hartz IV) se ocupa ampliamente TenoRIO, P. «El Tribunal Constitucional, la cláusula del Estado social, los derechos sociales », ob. cit., pp. 274-298.

${ }^{23}$ Cfr., al respecto, Fernández-Miranda Campoamor, A., «El Estado social...», ob. cit., pp. 174-175. 
Con arreglo a la doctrina y jurisprudencia citadas, el legislador gozará de un amplio margen de apreciación para revisar, restringir e incluso suprimir prestaciones sociales configuradas legalmente al amparo de los derechos sociales reconocidos en la Constitución. Ahora bien, conviene matizar que aunque el margen del legislador es amplio, no es absolutamente ilimitado. Ya que, como también ha manifestado el Tribunal Constitucional, a propósito de los arts. 9.2 y $35 \mathrm{CE}$, «no se puede privar al trabajador sin razón suficiente para ello de las conquistas sociales ya conseguidas» (STC 81/1982, de 21 de diciembre, FJ 3). La expresión "sin razón suficiente», es clave para interpretar el párrafo de esta sentencia, de tal manera que se admitiría una reversibilidad de las conquistas sociales, una introducción de medidas restrictivas de los derechos sociales (siempre que la realidad económica lo imponga) y siempre que la reversión sea fundada, razonable y no arbitraria o discriminatoria.

En este sentido, cualquier ley que restrinja o rebaje el nivel de prestaciones fijado en otra ley anterior constituye una intervención sobre el derecho, sobre su contenido, por lo que será necesario justificar la medida restrictiva acudiendo a la dogmática de los derechos fundamentales (respeto del contenido esencial constitucional y del principio de proporcionalidad). En estos casos, es al legislador al que corresponde (en los preámbulos de las normas) argumentar de forma detallada la utilización de las medidas restrictivas, evitando acudir única y exclusivamente al manido argumento de «la situación económica por la que atraviesa la economía española y la exigencia de cumplimiento de los objetivos de déficit público» (Real Decreto ley 20/2012, de 13 de julio, ya citado) o al «principio de estabilidad presupuestaria» (reserva de lo posible). Si se utiliza este argumento, habría de explicarse ampliamente por qué no existen recursos y dónde se destinan los que se tienen.

En otras palabras, ha de exigirse al legislador que cuando imponga recortes sociales, recortes de prestaciones públicas, para la consecución de determinados fines constitucionales, como el principio de estabilidad presupuestaria del art. $135 \mathrm{CE}$, acuda a la motivación de la decisión adoptada y al principio de proporcionalidad, que es susceptible de control judicial. Y ello con el objeto de evitar que la decisión se adopte de forma irracional o arbitraria (art. 9.3 CE), respetando, en todo caso, el lugar que ocupan los derechos sociales en el sistema axiológico-normativo de la Constitución, a la que, por otro lado, están sujetos todos los poderes públicos (art. 9.1 CE), y que les obliga, además, a promover la efectividad de la igualdad y a remover los obstáculos que impidan o dificulten su plenitud (art. 9.2 CE).

Los principios de igualdad en sentido material y de interdicción de la arbitrariedad pueden desplegar un papel importante en el control de la constitucionalidad de la justificación de las medidas legales de recorte de prestaciones públicas. A los límites sobre la amplia discrecionalidad del legislador en materia de derechos sociales se refiere una sentencia reciente del Tribunal Constitucional Federal alemán, de 14 de febrero de 2012. En ella se declara la inconstitucionalidad de determinadas normas del Estado 
de Hesse sobre remuneración de profesores, por vulneración de lo que el Tribunal llama «principio de alimentación» (como manutención o sustento) de los funcionarios públicos y que forma parte de la garantía institucional de la función pública proclamada en el art. 33.5 de la Constitución alemana. Según la elaboración que ha hecho de este principio el Tribunal Constitucional alemán, el empleador debe cuidar del bienestar del funcionario público y de su familia y mantenerlo adecuadamente de acuerdo con su rango, con la responsabilidad de su puesto de trabajo y la importancia que tiene para la sociedad en general la función pública que desempeña, y en correspondencia con el desarrollo de las circunstancias económicas y financieras generales y el nivel medio de vida ${ }^{24}$.

\section{UN DERECHO ESPECIALMENTE DEBILITADO: EL DERE- CHO A LA ASISTENCIA SANITARIA DE LOS INMIGRANTES IRREGULARES}

Como ya se ha mencionado, la actual coyuntura económica y la falta de recursos públicos para atender debidamente las prestaciones sociales, ha hecho que se hayan introducido por vía legislativa recortes en algunos de los derechos sociales básicos: sanidad, educación, servicios sociales o atención a la dependencia. Sin olvidar también el efecto demoledor que sobre el derecho a la vivienda está produciendo la crisis económica. En efecto, son miles las personas que al haber perdido su empleo no pueden afrontar el pago del préstamo hipotecario o el alquiler de la vivienda, dando lugar a la ejecución hipotecaria y al desahucio. Tanto la pérdida del empleo como de la vivienda están originando un problema social de extraordinaria importancia. En España, el año 2012 se ha cerrado con un número próximo a las 78.000 ejecuciones hipotecarias, situación previa al desahucio. Desde el año 2007 y hasta finales de 2012, las cifras rondan los 400.000 procedimientos de ejecución hipotecaria ${ }^{25}$.

${ }^{24}$ La referencia a esta sentencia de la Corte Federal alemana la tomamos de VAQUER CABAllería, M., «Derechos sociales, crisis económica...», ob. cit., pp. 91-92, cuya jurisprudencia puede resultar interesante al aplicar una doctrina similar a la manejada por el Tribunal Constitucional español sobre el control del legislador, «no ya a los recortes en los servicios públicos sino a los recortes en las remuneraciones de los servidores públicos», que también se han realizado en España. Recientemente, el Tribunal Constitucional portugués, en la sentencia 353/2012 de 5 de julio, ha declarado inconstitucional la supresión de las pagas extraordinarias de vacaciones y navidad de los empleados públicos durante los años 2012, 2013 y 2014. Sobre esta decisión pueden verses los comentarios de VILLALBA LaVA, M., en Diario La Ley, $\mathrm{n}^{\circ}$ 7907, 23 de julio de 2012; también en internet: (http:// pdfs.wke.es/9/2/7/4 /pd0000079274.pdf) y de GuILlÉn CARRAU, J., «El 1 Constitucional portugués ante las medidas de ajuste: la sentencia de 5 de abril de 2013», en Cuadernos Manuel Giménez Abad, $\mathrm{n}^{\circ}$ 5, junio 2013: (http://www.fundacionmgimenezabad.es/ images/Documentos/Cuadernos/5_cuadernos_junio2013.pdf).

${ }^{25}$ Cfr. el Diario El País de $\overline{3} 0$ de octubre de 2012 y de 7 de febrero de 2013, según los datos aportados por la Asociación Hipotecaria Española (AHE), que los ha extraído del Consejo General del Poder judicial: (http://economia.elpais.com/economia/ 2012/10/30/ 
Los recortes sociales están afectando especialmente a algunos colectivos vulnerables como el de los extranjeros, y en particular a los que se encuentran o devienen en situación administrativa irregular ${ }^{26}$. Veamos algunas consideraciones sobre el derecho a la asistencia sanitaria de este colectivo y las restricciones que al mismo se han establecido mediante la norma del Decreto ley. Efectivamente, el Real Decreto ley 16/2012, de 20 de abril, de medidas urgentes para garantizar la sostenibilidad del Sistema Nacional de Salud y mejorar la calidad y seguridad de sus prestaciones, además de introducir para los nacionales unos medidas de copago y prepago de algunas prestaciones sanitarias (farmacéutica, ortoprotésica y transporte sanitario no urgente), ha privado del derecho a la asistencia sanitaria, en las mismas condiciones que los españoles, a los extranjeros mayores de edad que no tengan permiso de

actualidad/1351613419_1 10881.html). De acuerdo con los datos del Instituto Nacional de Estadística (INE), 23.000 personas se encuentran sin hogar, de las que 10.513 (el 45,7 $\%$ ) son extranjeras, siendo la pérdida del trabajo el principal motivo por el que dichas personas se han quedado sin hogar. Debido a la privación de bienes materiales básicos, como la vivienda, se coloca a un número importante de familias en situaciones de extrema vulnerabilidad y de exclusión social. Resulta necesario acometer de forma urgente medidas específicas que contrarestren este problema social. Algunas se han adoptado, no sin cierto retraso, con los Decretos Ley 6/2012, de 9 de marzo, de medidas urgentes de protección a los deudores hipotecarios sin recursos y 27/2012, de 15 de noviembre, de medidas urgentes para reforzar la protección a los deudores hipotecarios. Se ha aprobado también la Ley $1 / 2013$, de 14 de mayo, de medidas para reforzar la protección a los deudores hipotecarios, reestructuración de deuda y alquiler social. Esta ley trata de complementar las medidas establecidas en las normas anteriores, perfeccionando y reforzando el marco de protección a los deudores hipotecarios que, por circunstancias excepcionales, han visto alterada su situación económica o patrimonial. Entre las medidas que contiene destacan las siguientes: 1) la suspensión inmediata y por un plazo de dos años de los desahucios de las familias que se encuentren en una situación de especial vulnerabilidad: las familias numerosas, las familias monoparentales con dos hijos a cargo, las que tienen un menor de tres años o algún miembro con discapacidad o dependiente, o en las que el deudor hipotecario se encuentre en situación de desempleo y haya agotado las prestaciones sociales, $o$ las víctimas de violencia de género; 2) se limitan los intereses de demora que pueden exigir las entidades de crédito, para las hipotecas constituidas sobre vivienda habitual, a tres veces el interés legal del dinero, prohibiéndose además la capitalización de dichos intereses; 3) se mandata al Gobierno para que impulse, con el sector financiero, la constitución de un fondo social de viviendas destinadas a las personas que hayan sido desalojadas de su vivienda habitual por el impago de un préstamo hipotecario. Acerca de otras medidas adoptadas por algunos poderes públicos para reducir los efectos destructivos sobre el derecho a una vivienda digna y adecuada (art. $47 \mathrm{CE}$ ), algunas controvertidas jurídicamente, como el alquiler forzoso de viviendas vacías a instancia de la Administración pública, vid. CARrillo, M. «L'impacte de la crisi sobre els drets...», ob. cit., pp 65-68.

${ }^{26} \mathrm{Vid}$. al respecto el trabajo de Aparicio Wilhelm, M., «Inmigración y crisis económica: la fragilidad de los derechos y su incidencia en las personas inmigradas». En Miguel Ángel Presno Linera (coord.): Crisis económica y atención a las personas y grupos vulnerables, Procuradora General del Principado y la Cátedra de amparo de derechos y libertades, Oviedo, 2012: (http://www.procuradorageneral.es/catedra/libro_digital_procura.php). 
residencia y que no acrediten la condición de asegurado ${ }^{27}$. Solamente recibirán asistencia sanitaria en los casos de atención en urgencias por enfermedad grave o accidente (conceptos de difícil interpretación y concreción jurídica) y de atención durante el embarazo, parto y postparto (modificación del art. 12.1 de la Ley Orgánica 4/2000, de 11 de enero, sobre derechos y libertades de los extranjeros en España y del art. 3 de la Ley 16/2003, de 28 de mayo, de cohesión y calidad del Sistema Nacional de Salud). Antes de la reforma introducida por el Real Decreto ley 16/2012, de 20 de abril, el art. 12.1 de la Ley Orgánica 4/2000, de 11 de enero, reconocía el derecho de asistencia sanitaria a los extranjeros (en las mismas condiciones que los españoles) por el mero hecho de estar inscritos en el padrón del municipio en el que tuvieran su domicilio habitual, esto es, con independencia de su situación legal administrativa ${ }^{28}$.

A los extranjeros irregulares y a otras personas que no reúnan la condición de asegurado o beneficiario del Sistema Nacional de Salud, se les ofrece la posibilidad de suscribir un convenio especial de prestación de asistencia sanitaria, siempre que cumplan determinados requisitos (acreditar la residencia efectiva en España durante al menos un año, estar empadronados en algún municipio español y no tener acceso a un sistema de protección sanitaria pública por cualquier otro título). Además se les exige el abono de 60 euros de cuota mensual, cuando «el suscriptor tiene menos de 65 años» y de 157 euros, «si el suscriptor tiene 65 o más años». Aun cuando a primera vista el precio no es muy elevado, la mayoría de los inmigrantes irregulares apenas

${ }^{27}$ Con la introducción en el Real Decreto-ley de la categoría de «asegurado», se vincula expresa y directamente el derecho a la asistencia sanitaria pública con el sistema contributivo de la Seguridad Social. Se mantiene, e incluso se refuerza, la conexión entre los Sistemas Nacional de Salud y de Seguridad Social.

${ }^{28}$ En general, sobre el derecho a la salud de los extranjeros, vid., entre otros, los siguientes trabajos: Arbeláez Rudas, M., «Los derechos sanitarios de los inmigrantes». En Aja, Eliseo, Montilla, José Antonio y Roig, Eduard (coords.): Las Comunidades Autónomas y la inmigración, Tirant lo blanch, Valencia, 2006, pp. 482-493; Arbeláez Rudas, M. y GARCía VÁzQueZ, S., «El derecho a la protección de la salud de los inmigrantes». En Aja, Eliseo (coord.): Los derechos de los inmigrantes en España, Tirant lo blanch, Valencia, 2009, pp. 437-462; Arbeláez RudAs, M., «La nueva regulación del derecho a la asistencia sanitaria de los extranjeros. Comentarios sobre las modificaciones en la redacción del artículo 12 LOEX». En Boza Martínez, Diego, Donaire Villa, Francisco Javier y Moya, David (coords.): Comentarios a la reforma de la ley de extranjería (LO 2/2009), Tirant lo blanch, Valencia, 2011, pp. 61 a 72; Jover Gómez Ferrer, R., Ortega Carballo, C. y Ripol Carulla, S., Derechos fundamentales de los extranjeros en España, Lex Nova, Valladolid, 2010, pp. 170 y ss.; AJA, E., Inmigración y Democracia, Alianza Editorial, Madrid, 2012, pp. 379 y ss. y Delgado Del Rincón, L.E., «Los derechos sociales de los extranjeros. En Matia Portilla, Francisco J., (dir.): Crisis e inmigración. Reflexiones interdisciplinares sobre la inmigración en España, Tirant lo blanch, Valencia, 2012, pp. 301-344 y «El derecho a la asistencia sanitaria de los inmigrantes irregulares: reflexiones sobre la reforma introducida por el Real Decreto-ley 16/2012, de 20 de abril». Revista de Estudios Políticos, $\mathrm{n}^{\circ}$ 162, 2013 (en imprenta). 
podrá afrontar el pago de esas cuotas, al encontrarse en condiciones económicas precarias. Por otro lado, la implantación de este tipo de convenios especiales, sin modulación alguna según los recursos de los destinatarios, podría considerarse una barrera económica que condiciona el ejercicio del derecho a la salud a un colectivo vulnerable, como es el de los inmigrantes irregulares. El convenio especial cubre las prestaciones de la cartera común básica de servicios asistenciales del Sistema Nacional de Salud, pero no las de la cartera común suplementaria (farmacéutica, ortoprotésica y transporte sanitario no urgente) $)^{29}$.

Creo que las reformas de la legislación de extranjería y sanidad (por el calado y entidad de la materia) introducidas por el Decreto ley 16/2012, debieran de haberse llevado a cabo mediante un proyecto de ley del Gobierno, tramitándose en las Cortes por el procedimiento legislativo ordinario o de urgencia y no acudiendo a la norma extraordinaria del Decreto ley; de la que, por otro lado, y a consecuencia también de la crisis económica y de la necesidad de introducir reformas urgentes, se está haciendo un uso desmedido por el Gobierno (28 en el año 2012) ${ }^{30}$. Mediante la norma del Decreto ley se

${ }^{29}$ Cfr. el Real Decreto 576/2013, de 26 de julio, por el que se establecen los requisitos básicos del convenio especial de prestación de asistencia sanitaria a personas que no tengan la condición de aseguradas ni de beneficiarias del Sistema Nacional de Salud. Esta norma publicada en el BOE de 27 de julio de 2013 (con entrada en vigor el día 1 de septiembre de 2013), se dicta en cumplimiento de lo previsto en el art. 3.5 de la Ley 16/2003, de 28 de mayo, y de la Disposición adicional tercera del Real Decreto 1192/2012, de 3 de agosto (que aludía a una Orden del Ministerio de Sanidad, Servicios Sociales e Igualdad).

${ }^{30}$ Esta utilización abusiva y desproporcionada por el Gobierno del Decreto-ley constituye una alteración del equilibrio institucional que en materia de fuentes (de producción normativa) ha de existir entre el Parlamento y el Gobierno, hasta el punto de que el Gobierno se ha convertido en el «señor de las fuentes». Vid. CARTABIA, M.: «Gli atti normativi del Governo tra Corte costituzionale e giudici»: (publicado en http://www.gruppodipisa. it/wp-content/uploads/2011/10/cartabia.pdf. También en «Il gobernó signore delle fonti? Introduzione». En Gli atti normativi del gobernó tra Corte costituzionale e giudici. M. Cartabia, E. Lamarque y P. Tanzarela (dirs.), Giappichelli, Turín, 2011, pp. 9 y ss.). En Italia puede apreciarse igualmente cómo en los últimos años se ha incrementado de modo desmesurado la publicación de Decretos-leyes: 114 en el periodo del 28/4/2006 al $28 / 4 / 2008$ y 118 del 29/4/2008 al 13/3/2013. Datos extraídos de la ponencia presentada por el profesor Andrea SimONCINI, «Crisi economica e suoi riflessi sull'assetto delle competenze», al Congreso sobre La crisi economica ed i suoi riflessi sull'ordinamento costituzionale, organizado por la Scuola Superiore Sant'Anna, Istituto DIRPOLIS y la Università di Pisa, Dipartimento di Giurisprudenza (22 de marzo de 2013), datos que evidencian, en opinión del profesor Simoncini, la preeminencia del poder ejecutivo sobre el legislativo en la evolución de la forma de gobierno parlamentaria. CARRILlo, M. «L'impacte de la crisi sobre els drets...», ob. cit., pp 56-60, expone cómo la «desbocada dinámica de afrontar las medidas jurídicas contra la crisis hace abstracción de la doctrina del Tribunal Constitucional sobre el decreto ley»; que, por regla general, se ha mostrado «muy flexible en relación con el juicio jurídico que corresponde hacer en cada caso sobre el presupuesto de hecho habilitante del art. 86.1 CE (en caso de extraordinaria y urgente necesidad)». Aunque, como expresa este autor, la permisividad jurisprudencial que se atribuye al Go- 
limita considerablemente el debate parlamentario en el Congreso de los Diputados y una participación más amplia de todos los grupos parlamentarios. Afecta al principio de división de poderes y demás principios esenciales del Estado de Derecho. Por el contrario, la utilización de la vía del proyecto de ley hubiera permitido la introducción de enmiendas parciales o la presentación de un texto alternativo. Incluso podrían haberse evitado la mayoría de los setenta y tres errores que contenía la norma (de diez artículos) y que fueron corregidos posteriormente en el Boletín Oficial del Estado (por cierto, algunas correcciones fueron de fondo y no meramente gramaticales). Por otro lado, no ha de olvidarse, como ha recordado el Tribunal Constitucional, que el ejercicio de esta potestad legislativa excepcional por el Gobierno «supone una sustitución del Parlamento por el Gobierno y constituye una excepción al procedimiento legislativo ordinario y a la participación de las minorías que éste dispensa» (STC 137/2011, de 14 de septiembre, FJ 4).

Las restricciones que sobre el derecho a la sanidad de los inmigrantes irregulares establece el Decreto ley 16/2012 constituyen un paso atrás en una conquista social consolidada, una regresión normativa en el disfrute del derecho. Ni el Preámbulo de la norma ni el debate parlamentario de convalidación contienen una argumentación suficiente que justifiquen las medidas limitadoras introducidas sobre el derecho a la sanidad de los inmigrantes irregulares (a diferencia de lo que se hace con otras medidas como las relacionadas con la prestación farmacéutica o los recursos humanos). De forma muy somera, y de pasada, se acude única y exclusivamente al socorrido argumento de la

bierno sobre el juicio de oportunidad, no legitima la utilización indiscriminada de los decretos leyes. La «fecundidad» y «feracidad» normativa para dictar Decretos-leyes parece que se ha extendido también en España a algunas Comunidades Autónomas, como pone de manifiesto, para las Islas Baleares, Blasco Esteve, A.: «Gobernar por decreto-ley» (publicado en http://www.diariodemallorca.es). Comparto la crítica que este autor realiza sobre la utilización habitual e indiscriminada que se está haciendo de los Decretos-leyes, hasta el punto de convertirse «en un modo alternativo de gobernar», en una «alteración inadmisible de las relaciones entre el órgano máximo del poder ejecutivo» y «el órgano de representación popular o poder legislativo», que es el que «expresa directamente la voluntad del titular de la soberanía». «La gravedad de la situación económica y la respuesta a la misma no deben hacer olvidar las garantías constitucionales y estatutarias ni los fundamentos del Estado de Derecho». Me sumo también a las críticas formuladas por DE La Iglesia Chamorro, A., «Los Decretos-leyes autonómicos en España: una aproximación crítica», Osservatorio sulle fonti: (Osservatoriosullefonti.it, fasc. 1/2013), pp. 5-6, 18-19 y 26, cuando considera que el Decreto-ley autonómico se ha convertido en algunas Comunidades Autónomas en un instrumento legislativo ordinario, desplazando incluso al Parlamento en su tarea de legislar; o cuando reconoce «la laxitud con la que se está interpretando el presupuesto de hecho habilitante o la indiscriminada aprobación de Decretosleyes sea sobre disposiciones con rango de ley o reglamentario», por no hablar también de las dificultades para controlar la constitucionalidad de estas disposiciones autonómicas con fuerza de ley, sobre las que puede consultarse también la obra de Donaire Villa, F.J., Las normas con fuerza de ley de las Comunidades Autónomas: las figuras del decreto legislativo y del decreto-ley autonómicos, Institut d'Estudis Autonòmics, Barcelona, 2012. 
coyuntura económica: «la grave dificultad económica por la que atraviesa el sistema sanitario público, con una alta morosidad y en insostenible déficit en las cuentas públicas sanitarias».

El derecho a la salud y a la asistencia sanitaria es un derecho social, de carácter prestacional, regulado en el art. 43 CE (dentro del Capítulo III del Título I de la Constitución). Por su naturaleza, el legislador goza de amplia libertad para configurar su contenido, de acuerdo con los recursos económicos disponibles y las prioridades de gasto. Incluso puede tomar en consideración el dato de la situación legal y administrativa de los extranjeros en España, y exigirles la autorización de su estancia o residencia como presupuesto para el ejercicio del derecho. Ahora bien, si se tiene en cuenta que estamos ante un derecho que tiene una clara conexión con el derecho a la vida e integridad física de las personas, del art. $15 \mathrm{CE}$, podría considerarse un derecho constitucional materialmente fundamental y de titularidad universal. Y ello, de acuerdo también con lo previsto en los arts. 25.1 de la Declaración Universal de Derechos Humanos y 12.1 del Pacto Internacional de Derechos Económicos, Sociales y Culturales. Es un derecho que, además, guarda una relación estrecha con la dignidad humana y que tiende a igualar a todas las personas en derechos por su condición de seres humanos. Por estas consideraciones, el legislador de urgencia, en el Decreto ley 16/2012, debiera de haber argumentado de forma explícita y suficiente por qué ha restringido, por motivos económicos y también por razón de la nacionalidad y de su situación administrativa, el derecho de asistencia sanitaria a los inmigrantes irregulares.

Algunas Comunidades Autónomas (el Parlamento de Navarra y los Consejos de Gobierno del Principado de Asturias y de la Junta de Andalucía) han presentado un recurso de inconstitucionalidad contra determinados preceptos del Decreto ley 16/2012. El Tribunal Constitucional, cuando examine los recursos, habrá de valorar si las medidas restrictivas introducidas por el legislador de urgencia, por motivos económico-presupuestarios, respetan o no su contenido esencial, y si superan o no el principio de proporcionalidad y sus criterios de idoneidad, adecuación y proporcionalidad en sentido estricto. Ahora bien, cuando el Tribunal Constitucional resuelva los recursos es probable que haya mejorado la situación económica del país y superado las dificultades que afectan al sistema sanitario público; desapareciendo, por tanto, las circunstancias de extraordinaria y urgente necesidad que sirvieron de fundamento al legislador para adoptar las medidas limitadoras del derecho.

Desde el punto de vista competencial, la sanidad es una materia de titularidad compartida en la que al Estado le corresponde establecer las bases o las condiciones básicas, que han de ser comunes para todas las Comunidades Autónomas, con el objeto de asegurar una cierta uniformidad y homogeneidad en el acceso de los ciudadanos a la sanidad. A las Comunidades Autónomas les compete el desarrollo y la ejecución de las bases o condiciones básicas fijadas por el Estado que, aun cuando han de ir en una misma dirección, de acuerdo con su capacidad de autogobierno y autonomía financiera, pue- 
den adaptarlas a sus circunstancias particulares mediante propuestas políticas propias que se concretarán, a su vez, en normas legislativas y reglamentarias. De este modo, conforme las Comunidades Autónomas han ido asumiendo competencias en sanidad, han ido surgiendo también diversos regímenes jurídicos sanitarios ${ }^{31}$. En otras palabras, se ha creado un sistema público sanitario que no es igual en todo el territorio del Estado, aunque, por medio de

${ }^{31}$ Algunas Comunidades Autónomas, con ocasión de las reformas estatutarias iniciadas a partir del año 2006, han incluido en el Estatuto de Autonomía, dentro de la parte relativa a los derechos estatutarios, un precepto en el que se reconoce, proclama o garantiza un derecho de todas las personas (carácter universal) a la sanidad (pública) o a la protección de la salud, aunque, como se indica en la mayoría de las normas estatutarias, de acuerdo con lo que se establezca en la ley, y dentro del marco de las competencias que, en materia de sanidad, productos farmacéuticos o de salud pública, hayan asumido las Comunidades Autónomas en sus Estatutos de Autonomía. El reconocimiento, con carácter universal, del derecho a la salud en las normas estatutarias permitiría atribuir la titularidad del derecho a los extranjeros (ya sean regulares o irregulares), incluso en condiciones de igualdad con los demás ciudadanos, aunque para ello se remitan a lo que dispongan las leyes (que pueden ser autonómicas y estatales). El Tribunal Constitucional se opondrá, sin embargo, a esta interpretación en la STC 31/2010, de 28 de junio (FJ 18), al considerar que la voluntad del legislador estatuyente no fue la de ampliar la titularidad de los derechos sociales a los extranjeros. Como es sabido, en relación con la naturaleza jurídica de los derechos estatutarios, el Tribunal Constitucional ha manifestado que aquellos preceptos de los Estatutos de Autonomía en los que se reconocen derechos o principios rectores de la política social y económica, estos han de estar conectados con una materia que haya sido adquirida como competencia autonómica en el Estatuto, y que para que tengan plena eficacia jurídica y sean exigibles directamente ante la jurisdicción ordinaria es necesario que el legislador autonómico regule su régimen jurídico (SSTC 247/2007, de 12 de diciembre, FJ 15 y $31 / 2010$, de 28 de junio, FJ 16). Sobre los derechos estatutarios y su naturaleza jurídica existen ya numerosos trabajos en la doctrina, pueden destacarse entre otros: FERRERES Comella, V., Biglino Campos, P. y Carillo, M., Derechos, deberes y principios en el nuevo Estatuto de Autonomía de Cataluña, Centro de Estudios Políticos y Constitucionales, Madrid, 2006, pp. 9 y ss.; Diez Picazo Giménez, L.Ma, «¿Pueden los Estatutos de Autonomía declarar derechos, deberes y principios?», Revista Española de Derecho Constitucional, $\mathrm{n}^{\circ}$ 78, 2006, pp. 63 y ss.; CaAmaño Domínguez, F., «Sí, pueden (Declaraciones de derechos y Estatutos de Autonomía)», Revista Española de Derecho Constitucional, nº 79, 2007, pp. 33 y ss.; Diez Picazo Giménez, L.M ${ }^{\mathrm{a}}$, «De nuevo sobre las declaraciones estatutarias de derechos: respuesta a Francisco Caamaño», Revista Española de Derecho Constitucional, $n^{\circ} 81,2007$, pp. 63 y ss.; Balaguer CALlejón, F. «Derechos, principios y objetivos en los Estatutos de Autonomía reformados», Anuario Jurídico de la Rioja, no 13, 2008, pp. 13 y ss.; Castellá Andreu, J.Ma. y Grammond, S. (coords.), Diversidad, derechos fundamentales y federalismo. Un diálogo entre Canadá y España, Atelier, Barcelona 2010, pp. 15 y ss.; Cámara Villar, G., "Veste y realidad de los derechos estatutarios», Revista de Estudios Políticos, nº 151, 2011, pp. 57 y ss.; Villaverde Menéndez, I., La igualdad en la diversidad. Forma de Estado y derechos fundamentales, Centro de Estudios Políticos y Constitucionales, Madrid, 2012, pp. 105-137; Torres Muro, I., «Derechos sociales y Comunidades Autónomas». En Constitución y Democracia: ayer y hoy. Libro Homenaje a Antonio Torres del Moral, vol. III, Universitas, S.A., Universidad Nacional de Educación a Distancia, Centro de Estudios Políticos y Constitucionales, Madrid, 2012, pp. 3539 y ss. y también en este Libro homenaje, BARCELó, M., «La azarosa vida de los derechos 
la legislación básica, el Estado, para garantizar una igualdad mínima de todos los ciudadanos (art. 149.1, $1^{\circ}$ y $16^{\circ} \mathrm{CE}$ ), ha establecido una cartera común de servicios del Sistema Nacional de Salud y sus beneficiarios ${ }^{32}$. Esta cartera común integraría el contenido mínimo del derecho a la salud respecto de los nacionales y extranjeros residentes que tengan la condición de asegurado. Las Comunidades Autónomas pueden superarlo mediante la creación de una cartera de servicios complementaria cuyos beneficiarios serían los residentes que tuvieran la condición de asegurado ${ }^{33}$. Esta cartera complementaria integraría, a su vez, un contenido adicional del derecho.

Para los inmigrantes irregulares mayores de edad, el contenido mínimo del derecho a la salud, según la legislación básica del Estado, es menor pues comprendería solamente la atención en urgencias por enfermedad grave o accidente (que es gratuita) y el acceso a la cartera común básica de servicios asistenciales, previa suscripción de un convenio especial y el abono de unas cuotas, en tanto en cuanto regularizan su situación.

sociales. Del cuestionamiento de su regulación autonómica a la supuesta inevitabilidad de su restricción», pp. 3513 y ss.

${ }^{32}$ La cartera común de servicios del Sistema Nacional de Salud presenta las siguientes modalidades: la cartera común básica de servicios asistenciales; la cartera común suplementaria y la cartera común de servicios accesorios. La cartera común básica de servicios asistenciales comprende las actividades asistenciales de prevención, diagnóstico, tratamiento y rehabilitación que se realicen en centros sanitarios o sociosanitarios, así como el transporte sanitario urgente. Estas prestaciones son totalmente gratuitas, están cubiertas de forma completa por la financiación pública. La cartera común suplementaria incluye las prestaciones farmacéutica, ortoprotésica, la de productos dietéticos y el transporte sanitario no urgente. La cartera común de servicios accesorios incluye las actividades, servicios o técnicas no esenciales pero de apoyo a la mejora de una patología crónica. Las prestaciones de la cartera común suplementaria y las de la de servicios accesorios se sufragan con fondos públicos y con aportaciones económicas de los usuarios (arts. 8, bis, ter y quáter de la Ley 16/2003, de 28 de mayo, de cohesión y calidad del Sistema Nacional de Salud, modificado y añadidos por el Real Decreto-ley 16/2012, de 20 de abril). EscoBAR RocA, G., «Los derechos fundamentales sociales y la protección de la salud... ...», ob. cit., pp. 139-140 y «El derecho a la protección de la salud». Derechos sociales y tutela antidiscriminatoria, ob. cit., pp. 1123-1124, expone cómo el catálogo de prestaciones que integran la cartera común de servicios del Sistema Nacional de Salud, regulado en la Ley 16/2003, de 28 de mayo, de cohesión y calidad del Sistema Nacional de Salud, conforma el contenido del derecho de protección a la salud y se proyecta sobre el concepto de salud por el que opta el art. $43 \mathrm{CE}$.

${ }^{33}$ Las Comunidades Autónomas, en el ámbito de sus competencias, pueden aprobar sus respectivas carteras de servicios que incluirán, al menos, la cartera común de servicios del Sistema Nacional de Salud en sus modalidades básica de servicios asistenciales, suplementaria y de servicios accesorios, garantizándose a todos los usuarios del mismo. Para aprobar la cartera de servicios complementaria de una Comunidad Autónoma, ha asegurarse preceptivamente la financiación de la cartera común de servicios. Las Comunidades Autónomas asumirán, con cargo a sus propios presupuestos, todos los costes de aplicación de la cartera de servicios complementaria a las personas que tengan la condición de asegurado (art. 8, quinquies, 1, 3 y 7 de la Ley 16/2003, de 28 de mayo, añadido por el Real Decreto-ley 16/2012, de 20 de abril). 
El Estado tiene competencia exclusiva en materia de bases y coordinación general de la Sanidad (ex art. 149.1.16 CE). El desarrollo de este título competencial se lleva a cabo, entre otras leyes, por la citada Ley de cohesión y calidad del Sistema Nacional de Salud, en la que, según se ha dicho, se establecen las prestaciones y servicios del Sistema Nacional de Salud (contenido mínimo del derecho a la salud), así como sus beneficiarios (titularidad del derecho ${ }^{34}$.

Consideramos que del mismo modo que se ha permitido a las Comunidades Autónomas, en desarrollo de las bases del Estado, aprobar sus propias carteras de servicios y establecer prestaciones adicionales para sus residentes (ámbito objetivo del derecho), podría admitirse también que las Comunidades Autónomas ampliaran por normas autonómicas la titularidad de las prestaciones y servicios (ámbito subjetivo del derecho). De esta manera podría facilitarse su acceso, en determinados supuestos y con el cumplimiento de ciertas condiciones, a personas que no tuvieran la condición de asegurado, como es el caso de los inmigrantes irregulares.

Las Comunidades Autónomas han reaccionado de forma diversa a la hora de aplicar y desarrollar por normas autonómicas el Real Decreto-ley 16/2012 ${ }^{35}$. Así, existe un primer grupo de Comunidades Autónomas como Madrid, Castilla-La Mancha, Cantabria, La Rioja, Islas Baleares, Extremadura, Aragón o Murcia, en las que, desde el 1 de septiembre de 2012, el Gobierno autonómico aplica de forma estricta el Real Decreto-ley 16/2012, negando la tarjeta y la asistencia sanitaria a los inmigrantes irregulares, salvo en los supuestos contemplados en el propio Decreto-ley: atención en urgencias, mujeres embarazadas y menores de edad.

Un segundo grupo de Comunidades Autónomas estaría constituido por aquellas Comunidades que anunciaron, desde un primer momento y a través de sus representantes políticos, la voluntad de no aplicar estrictamente el Real Decreto-ley 16/2012, facilitando la asistencia sanitaria a los inmigrantes irregulares o, dicho de otro modo, ampliando subjetiva y objetivamente la prevista en la norma estatal. En este grupo se incluirían Andalucía, Asturias, Cataluña y País Vasco. Incluso algunas de ellas reaccionaron frente al Decreto-ley 16/2012 interponiendo un recurso de inconstitucionalidad contra determinados preceptos (Asturias y Andalucía). Desde los Gobiernos de algunas de estas Comunidades Autónomas, y a través de la Consejería competente en materia de sanidad o salud, se han elaborado normas autonómicas (la mayoría de ellas instrucciones internas que en algunos casos ni siquiera se publican oficialmente) en las que se establece el acceso de los inmigrantes irregulares a las prestaciones sanitarias del servicio de salud autonómico

${ }^{34}$ Véase, en este sentido, la STC 136/2012, de 19 de junio (FJ 5).

${ }^{35}$ Una información más amplia y detallada sobre la reacción de las Comunidades Autónomas frente al Real Decreto-Ley 16/2012 y las normas dictadas por estas en su ejecución y desarrollo, puede verse en nuestro trabajo: Delgado Del Rincón, L.E., «El derecho a la asistencia sanitaria de los inmigrantes ...», ob. cit. (en imprenta). 
en las mismas condiciones que los ciudadanos de la Comunidad Autónoma. Para ello, se les otorga un documento acreditativo o una tarjeta especial (que puede ser provisional, susceptible de prórroga), aunque para su obtención se exige el cumplimiento de determinados requisitos como el carecer de otro sistema de cobertura sanitaria, el empadronamiento por un periodo de tiempo mínimo en un municipio de la Comunidad Autónoma (que difiere de unas Comunidades a otras), o no superar una cuantía de ingresos determinada.

Existiría todavía un tercer grupo de Comunidades Autónomas compuesto por aquellas Comunidades que han desarrollado otros mecanismos o procedimientos para continuar prestando asistencia sanitaria a los inmigrantes irregulares. Así, en algunas de ellas (Castilla y León y Valencia) se han adoptado determinadas instrucciones o circulares por órganos de las Consejerías competentes en materia sanitaria en las que se reconoce la asistencia sanitaria a los inmigrantes irregulares, aunque con la obligación de facturar los servicios prestados. Sin perjuicio de que se establezca también la posibilidad de que surjan situaciones de facturas impagadas, al no poder abonar su importe los inmigrantes irregulares por carecer de recursos económicos suficientes. De ahí que se contemple en esas normas que las facturas se satisfagan con cargo a los servicios sociales de la Comunidad, de los Ayuntamientos o de organizaciones no gubernamentales. A partir del 1 de septiembre de 2013, fecha en que entra en vigor el Real Decreto 576/2013, de 26 de julio, elaborado por el Ministerio de Sanidad, Servicios Sociales e Igualdad, las Consejerías competentes en materia de Sanidad, a través de los órganos competentes, proponen a las personas que no tengan la condición de aseguradas ni de beneficiarias del Sistema Nacional de Salud la firma de un convenio especial para recibir la prestación de asistencia sanitaria, en las condiciones establecidas en dicha norma.

Dentro de este tercer grupo, otras Comunidades Autónomas (Galicia, Navarra y Canarias), a través de órganos de las Consejerías competentes en materia sanitaria, han dictado también normas autonómicas (instrucciones o circulares internas), en las que se prevén programas de salud pública o de carácter social y/o se habilitan procedimientos para la elaboración de un registro y para la obtención de un documento que acredite a los inmigrantes irregulares como usuarios del servicio de salud autonómico.

Se condiciona también el acceso a dichos programas y documentos acreditativos a que los inmigrantes irregulares cumplan determinados requisitos como el empadronamiento por un periodo de tiempo mínimo en un municipio de la Comunidad Autónoma, el no superar una cuantía de ingresos determinada o el carecer de otro sistema de cobertura sanitaria.

El Gobierno de la Nación ha presentado ante el Tribunal Constitucional un conflicto positivo de competencias contra los Gobiernos Vasco y Navarro, al haber dictado unos Decretos (114/2012, de 26 de junio y 117/2012, de 31 de octubre, respectivamente), en los que se ampliaba la cobertura sanitaria a las personas que habían sido excluidas por el Decreto ley 16/2012. El Gobierno 
considera que algunas de las disposiciones impugnadas afectan a materias de competencia exclusiva del Estado y contradicen la legislación básica estatal en materia de sanidad interior (art. 149.1.16 CE). En el caso del Decreto Vasco, el Gobierno de la Nación solicitó, asimismo, la suspensión de la norma. El Tribunal ha resuelto el incidente de suspensión en el ATC 239/2012, de 12 de diciembre, en el que acuerda levantar la suspensión de algunos de los preceptos del Decreto del Gobierno Vasco, en concreto, los que permiten dar asistencia sanitaria a determinadas personas excluidas por el Decreto ley 16/2012, entre los que se encuentran los inmigrantes irregulares. El Alto Tribunal, ponderando los bienes jurídicos y los posibles perjuicios económicos o que para la salud pública e individual pueden derivarse del levantamiento o no de la suspensión del Decreto, establece de forma clara que «el derecho a la salud y el derecho a la integridad física de las personas afectadas por las medidas impugnadas, así como la conveniencia de evitar riesgos para la salud del conjunto de la sociedad, poseen una importancia singular en el marco constitucional, que no puede verse desvirtuada por la mera consideración de un eventual ahorro económico que no ha podido ser concretado» (FJ 5).

\section{A MODO DE CONCLUSIÓN}

La crisis económica que desde hace unos años están atravesando los países del continente europeo -que afecta con mayor intensidad a los del sur-, está agravando la crisis de la forma del Estado social y alterando sustancialmente alguno de sus elementos constitutivos como es el reconocimiento y efectividad de los derechos sociales. Según se ha dicho, algunos de los efectos de esta crisis económico-financiera, como el incremento desmesurado del paro o la inyección por el Estado de importantes cantidades de dinero público a entidades bancarias, están produciendo una disminución de la capacidad económica del Estado para afrontar la protección social de las crecientes necesidades de la población, en detrimento de una igualdad real y efectiva de todos los ciudadanos. En definitiva, la situación de crisis económica está generando determinados problemas que ponen de manifiesto la eficacia jurídica limitada de la cláusula del Estado social, porque siendo una cláusula finalista que persigue una sociedad más justa e igualitaria, depende para la consecución de sus fines de diferentes opciones y circunstancias políticas y económicas.

Los derechos sociales tienen una dimensión económicamente relevante, su efectividad depende -en virtud de la denominada cláusula de la «reserva de lo posible»- de la capacidad económica, financiera y presupuestaria del Estado. Se trata, por tanto, de una cláusula que puede erigirse en un límite a la efectividad de los derechos sociales. En situaciones de crisis económica, los poderes públicos, particularmente el legislativo, la utilizan de forma recurrente para justificar medidas restrictivas de derechos sociales. Desde posiciones doctrinales contrarias a la adopción de estas medidas limitadoras se opone el principio de irreversibilidad de los derechos sociales como 
instrumento jurídico idóneo para reducir el impacto de la crisis económica sobre los derechos sociales, asegurando así un mínimo existencial, un nivel mínimo de igualdad social. Adhiriéndonos a la posición mayoritaria de la doctrina y a la jurisprudencia del Tribunal Constitucional, consideramos que la admisión del principio de irreversibilidad de las conquistas sociales impediría la gobernación y la viabilidad del Estado. De ahí que sea necesario que el legislador disponga de la facultad de corregir situaciones (revisar o restringir prestaciones sociales) que sean eventualmente insostenibles por circunstancias socioeconómicas. Ahora bien, aunque el margen de actuación del legislador es amplio, no es absolutamente ilimitado, siendo igualmente necesario que toda medida restrictiva de los niveles de protección social se someta al control de constitucionalidad a través de los criterios de proporcionalidad y de razonabilidad y de respeto al núcleo esencial (mínimo «existencial») de los derechos sociales. En otras palabras, ha de exigirse al legislador que cuando imponga recortes sociales, para la consecución de determinados fines constitucionales, como el principio de estabilidad presupuestaria del art. $135 \mathrm{CE}$, acuda a la motivación de la decisión adoptada y al principio de proporcionalidad, que es susceptible de control judicial.

Los recortes sociales están afectando especialmente a algunos colectivos vulnerables como el de los extranjeros, y en particular los que se encuentran en situación administrativa irregular. El Real Decreto ley 16/2012, de 20 de abril, que modifica la legislación sanitaria de extranjería, ha privado del derecho a la asistencia sanitaria, en las mismas condiciones que los españoles, a los extranjeros mayores de edad que no tengan permiso de residencia y que no acrediten la condición de asegurado, salvo en los casos de atención en urgencias por enfermedad grave o accidente y de atención durante el embarazo, parto y postparto. Ni el Preámbulo de la norma ni el debate parlamentario de convalidación contienen una argumentación suficiente que justifiquen las medidas limitadoras introducidas sobre el derecho a la sanidad de los inmigrantes irregulares. A este colectivo se les ofrece la posibilidad de suscribir un convenio especial de prestación de asistencia sanitaria, mediante el pago de unas cuotas y siempre que se cumplan determinados requisitos. Aun cuando las cuotas no son elevadas, la mayoría de los inmigrantes irregulares apenas podrá afrontar el pago de esas cuotas, al encontrarse éstos en condiciones económicas precarias.

Las Comunidades Autónomas han reaccionado de forma diversa a la hora de aplicar y desarrollar por normas autonómicas el Real Decreto-ley 16/2012. Así, mientras unas Comunidades Autónomas lo aplican de forma estricta; otras no lo aplican, facilitando la asistencia sanitaria a los inmigrantes irregulares en las mismas condiciones que los ciudadanos de la Comunidad; e incluso existen otras Comunidades Autónomas que han desarrollado mecanismos o procedimientos para continuar prestando asistencia sanitaria a los inmigrantes irregulares. Nos encontramos así ante una situación de heterogeneidad normativa, con normas autonómicas de diverso y desigual contenido, 
algunas de ellas de carácter provisional (instrucciones y circulares), al estar todavía pendientes de ulteriores desarrollos normativos. Esta situación de heterogeneidad normativa puede dar lugar a un no deseable «efecto llamada», a un desplazamiento de los inmigrantes irregulares desde aquellas Comunidades Autónomas que no les conceden el acceso a las prestaciones sanitarias adicionales a otras Comunidades que sí se las ofrecen, a pesar incluso de la exigencia de ciertos requisitos como el estar empadronados en un municipio de la Comunidad Autónoma por un periodo de tiempo determinado.

RESUMEN: En este trabajo el autor expone cómo el contexto socioeconómico actual y la crisis económica en la que nos hallamos inmersos está agudizando la crisis del Estado social. Se hace un breve diagnóstico de la crisis de este modelo de Estado y de su incidencia sobre uno de sus elementos estructurales, los derechos sociales. El autor se ocupa también del examen de la denominada cláusula de la «reserva de lo posible», como límite a la efectividad de los derechos sociales, y de su conexión con otro problema, el de la reversibilidad o no de las normas reconocedoras de derechos sociales. Los recortes sociales están afectando especialmente a algunos colectivos vulnerables como el de los extranjeros irregulares. En este artículo se analiza también la restricción que sobre el derecho a la asistencia sanitaria de este colectivo se ha llevado a cabo por el Real Decreto-ley 16/2012, de 20 de abril y la diferente ejecución que de él han realizado algunas Comunidades Autónomas.

PALABRAS CLAVE: Derechos sociales, crisis económica, irreversibilidad de los derechos sociales, inmigración.

ABSTRACT: In this paper the author discusses how the present socio-economic context and the economic crisis in which we find ourselves is exacerbating the crisis of the welfare state. It makes a brief diagnosis of the crisis of the model of state and their impact on its structural elements, social rights. The author also deals with the examination of the clause called "possible reserves», as a limit to the effectiveness of social rights, and its connection with another problem, reversibility or otherwise of social rights laws. The welfare cuts are affecting some groups especially vulnerable as irregular foreigners. This article also analyzes the restriction on the right to health care for this group was carried out by Real Decreto-ley 16/2012, of April 20, and the different implementing it have been some Comunidades Autónomas.

KEYWORDS: Social rights, economic crisis, irreversibility of social rights, immigration.

Recibido: 20.07.2013

Aceptado: 02.09.2013 